\title{
Natural Convection and Entropy Generation in a Square Cavity with Variable Temperature Side Walls Filled with a Nanofluid: Buongiorno's Mathematical Model
}

\author{
Mikhail A. Sheremet ${ }^{1,2}$, Teodor Grosan ${ }^{3}$ and Ioan Pop ${ }^{3, *}$ \\ 1 Department of Theoretical Mechanics, Tomsk State University, Tomsk 634050, Russia; \\ michael-sher@yandex.ru \\ 2 Department of Nuclear and Thermal Power Plants, Tomsk Polytechnic University, Tomsk 634050, Russia \\ 3 Department of Mathematics, Babeş-Bolyai University, Cluj-Napoca 400084, Romania; \\ tgrosan@math.ubbcluj.ro \\ * Correspondence: popm.ioan@yahoo.co.uk; Tel.: +4-026-405-300
}

Received: 15 May 2017; Accepted: 26 June 2017; Published: 5 July 2017

\begin{abstract}
Natural convection heat transfer combined with entropy generation in a square cavity filled with a nanofluid under the effect of variable temperature distribution along left vertical wall has been studied numerically. Governing equations formulated in dimensionless non-primitive variables with corresponding boundary conditions taking into account the Brownian diffusion and thermophoresis effects have been solved by finite difference method. Distribution of streamlines, isotherms, local entropy generation as well as Nusselt number has been obtained for different values of key parameters. It has been found that a growth of the amplitude of the temperature distribution along the left wall and an increase of the wave number lead to an increase in the average entropy generation. While an increase in abovementioned parameters for low Rayleigh number illustrates a decrease in average Bejan number.
\end{abstract}

Keywords: natural convection; square cavity; sinusoidal wall temperature; nanofluids; Brownian diffusion; thermophoresis; numerical method

\section{Introduction}

Natural convection in enclosures has received considerable attention during the last several decades due to its effect on thermal performance in many engineering applications, including the operation of solar collectors, cooling of electronic equipment, hot- and chilled-water storage tanks, ovens, furnaces, and many others. Much research work, both theoretical and experimental, has been done on the convective heat transfer processes in two-dimensional enclosures, where the common model is the square or rectangular enclosure heated horizontally or vertically. The details of the natural-convection theory in enclosures has been presented in books by Minkowycz et al. [1], Yang [2], Pop and Ingham [3], Bejan [4], and Shenoy et al. [5], among others (see Saeid and Yaacob [6]). It seems, however, that little work has been done for the natural convection in cavities with boundary walls having nonuniform temperatures. Several studies (Vahl Davis [7], Ostrach [8], Hortman et al. [9], and Barakos et al. [10]) considered the natural convection in a differentially heated enclosure. Fu et al. [11] studied numerically the natural convection in an enclosure with the heated wall of the enclosure divided into two, higher- and lower-temperature regions, and the temperature of the cold wall maintained at a constant. Their results show that the local Nusselt number distribution varies drastically at the intersection of the higher and lower-temperature regions. Xia et al. [12] studied the buoyancy-driven laminar flow in a two-dimensional square enclosure when varying 
sinusoidal perturbation is imposed on the hot vertical wall. These authors found that the perturbations destabilized the flow, higher amplitudes lead to lower critical Rayleigh numbers for the flow transitions. Lakhal et al. [13] studied numerically the transient heat transfer by laminar natural convection in a square cavity partially heated from below using a finite-difference procedure. The temperature of the heating element is uniform, but its magnitude varies sinusoidally with time, oscillating about a fixed mean value. The opposite cold wall is maintained at a constant temperature, while the rest of the bottom wall and the vertical walls are adiabatic. Several researchers have studied the periodic natural convection in two-dimensional enclosures. The phenomenon of natural convection in an enclosures heated periodically from the side has been considered by Lage and Bejan [14] and Kwak et al. [15]. The problem of steady natural convection in a two-dimensional enclosure with sinusoidal upper wall temperature has been studied numerically by Sarris et al. [16]. The applied sinusoidal temperature is symmetric with respect to the mid-plane of the enclosure, and the bottom and side walls are adiabatic. It should be also mentioned that Sheremet and Pop $[17,18]$ numerically analyzed free convection in a porous square [17] and in a wavy [18] cavity under the effect of sinusoidal temperature distributions on both side walls filled with a nanofluid using the mathematical nanofluid model proposed by Buongiorno [19].

Calculation of entropy generation is an excellent tool to obtain the energy losses inside the system. Different types of thermal systems are related to the mechanism of irreversibility which can be described with the help of entropy generation and are relevant to viscous dissipation, magnetic field, heat and mass transfer, etc. To enhance this irreversibility process, various researchers used first law of thermodynamics but they found that the obtained results are unsatisfactory (see Bejan [20-22]). Later, many authors used the second law of thermodynamics to optimise these irreversibilities and observed that second law of thermodynamics is more effcient and reliable as compared to the first law of thermodynamics. The entropy generation was investigated for different media. For instance, Rashidi et al. [23] investigated entropy generation over a rotating permeable disk in a nanofluid under the influence of Magnetohydrodynamics (MHD) effect. They found that the disk source is the major point that helps in entropy generation. Further, Komurgoz et al. [24] studied the magnetic field effect on the entropy generation within an inclined porous channel. It has been shown They found that maximum entropy generation can be achieved in the absence of zero magnetic fields and zero porosity. Butt and Ali [25] examined the influence of irreversibility on unsteady free convective hydromagnetic flow with thermal radiation through a vertical porous plate. The entropy generation in a porous cavity under the influence of the magnetic field has been considered by Mahmud and Fraser [26] and they concluded that with the increment in the magnetic field, entropy generation increases. Finally, we mention the recently published papers by Sheremet et al. $[27,28]$ and Bondareva et al. [29] on the entropy generation through natural convection heat transfer in nanofluids inside cavities using the mathematical nanofluid model proposed by Tiwari and Das [30].

It is worth mentioning that the basic theory of entropy generation is widely presented in a seminal work by Bejan [20-23]. The application of entropy generation is also reviewed by Oztop and Al-Salem [31]. A numerical study on mixed convection and entropy generation for a nanofluid filled cavity is given by Nayak et al. [32]. The entropy generation and Bejan number are evaluated to demonstrate the thermodynamic optimization of the mixed convection and they showed that the heat transfer rate increases remarkably by the addition of nanoparticles. Selimefendigil and Oztop [33] studied the effect of the magnetic field on natural convection and entropy generation in a cavity filled by a nanofluid having different shaped obstacles inside the cavity. They observed that averaged heat transfer reduces by $21.35 \%, 32.85 \%$ and $34.64 \%$ for the cavity with circular, diamond and squared shaped obstacles, respectively, compared to a cavity without obstacles at $R a=10^{6}$. It is also important to point out the very recently published paper by Kefayati et al. [34] on simulation of natural convection and entropy generation of non-Newtonian nanofluid in an inclined cavity using Buongiorno's mathematical model (Part II, entropy generation). The review paper on entropy generation in nanofluids flow by Mahian et al. [35] should also be mentioned in this context. 
Cooling is one of the most important technical challenges facing many diverse industries, including microelectronics, transportation, solid-state lighting, and manufacturing. The review paper by Manca et al. [36] notices that the heat transfer can be enhanced by increasing the thermal conductivity of the fluid. This is possible by adding small size metallic or oxyde-metallic particles to the base fluid. When the size of added particles is in the range of nanometers, the so called nanofluid is obtained and it was shown that this fluid posses enhanced thermal properties. (see Choi [37]). It is worth mentioning that many references on nanofluids can be found in the books by Das et al. [38], Nield and Bejan [39], and Shenoy et al. [5], and in the review papers by Buongiorno [19], Buongiorno et al. [40] and Mahian et al. [41], etc. Several published papers, such as those by Sivasankaran and Pan [42], Alsabery et al. [43,44], and Oztop et al. [45] have considered the natural convection in cavities filled by nanofluids where the temperature on the boundaries is non-uniform, having a sinusoidal distribution.

The main objective of the present study is to analyze the natural convection combined with entropy generation in a square cavity filled with a nanofluid with sinusoidal temperature distribution on one side wall using Buongiorno's nanofluid model [19]. To our best of knowledge this problem has not been considered before, so that the reported results are new and original. Periodic heating has strong implications for the glass industry, where the main objective is to increase the mixing of the glass melt. Also, the active walls may be subject to non-uniform temperature distribution due to shading or other effects in different fields such as solar energy collection and cooling of electronic components.

\section{Basic Equations}

We consider the natural convective fluid flow and heat transfer within a square cavity filled with a nanofluid based on water and solid nanoparticles. A schematic geometry of the problem under consideration is shown in Figure 1 with dimensional Cartesian coordinates, where $L$ is the size of the cavity. The cavity has adiabatic horizontal walls and the right vertical wall is kept at a constant temperature $T_{c}$. The left vertical wall have variable temperature distribution according to the vertical coordinate as follows:

$$
T(\bar{y})=T_{h}+\varepsilon\left(T_{h}-T_{\mathcal{C}}\right)\left[1-\cos \left(\frac{2 \pi \kappa \bar{y}}{L}\right)\right] \text { at } \bar{x}=0
$$

where $T_{h}>T_{c}, \varepsilon$ is amplitude of the variable hot-wall temperature and $\kappa$ is wave number of the hot-wall temperature.

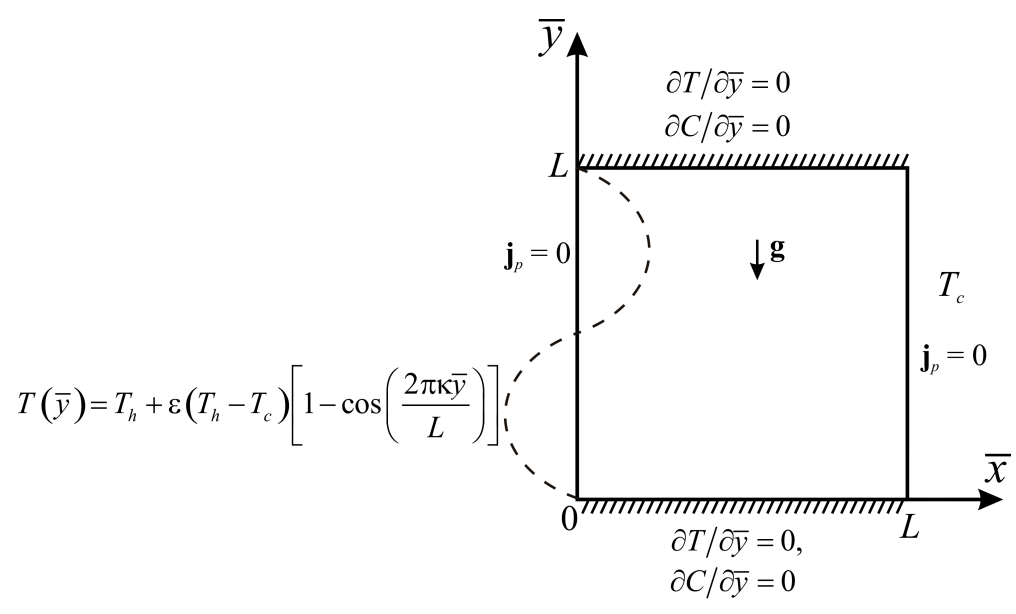

Figure 1. Physical model and coordinate system.

The thermophysical properties of the fluid are assumed constant, except for the density, the buoyancy force effect being described by the Boussinesq approximation. Under these assumptions, 
the governing equations for nanofluid can be written as follows taking into account the effects of Brownian diffusion and thermophoresis [19]:

$$
\begin{gathered}
\nabla \cdot \mathbf{V}=0 \\
\rho_{f}\left[\frac{\partial \mathbf{V}}{\partial t}+(\mathbf{V} \cdot \nabla) \mathbf{V}\right]=-\nabla p+\mu \nabla^{2} \mathbf{V}+\left[C \rho_{p}+(1-C) \rho_{f 0}\left(1-\beta\left(T-T_{\mathcal{C}}\right)\right)\right] \mathbf{g} \\
\frac{\partial T}{\partial t}+(\mathbf{V} \cdot \nabla) T=\alpha \nabla^{2} T+\delta\left[D_{B} \nabla C \cdot \nabla T+\left(D_{T} / T_{C}\right) \nabla T \cdot \nabla T\right] \\
\rho_{p}\left(\frac{\partial C}{\partial t}+(\mathbf{V} \cdot \nabla) C\right)=-\nabla \cdot \mathbf{j}_{p}
\end{gathered}
$$

where $\mathbf{V}$ is the velocity vector, $T$ is the nanofluid temperature, $C$ is the nanoparticle volume fraction, $t$ is the time, $p$ is the fluid pressure, $\mathbf{g}$ is the gravity vector, $D_{B}$ is the Brownian diffusion coefficient, $D_{T}$ is the thermophoretic diffusion coefficient, $\mathbf{j}_{p}=-\rho_{p}\left[D_{B} \nabla C+\left(D_{T} / T_{c}\right) \nabla T\right]$ is the nanoparticles mass flux, $\rho_{f 0}$ is the reference density of the fluid, $\alpha, \mu, \rho_{p}$ denote the thermal diffusivity of the nanofluid, the dynamic viscosity, nanoparticle mass density, respectively, $\delta$ is a quantity defined by $\delta=\left(\rho C_{p}\right)_{p} /\left(\rho C_{p}\right)_{f}, C_{p}$ is the heat capacity at constant pressure, $\left(\rho C_{p}\right)_{f}$ is heat capacity of the base fluid, $\left(\rho C_{p}\right)_{p}$ is effective heat capacity of the nanoparticle material and $\beta$ is the coefficient of thermal expansion.

Further on, we will linearize the momentum equation considering the Boussinesq approximation and dilute form of nanoparticle concentration [17,18]:

$$
\rho_{f 0}\left[\frac{\partial \mathbf{V}}{\partial t}+(\mathbf{V} \cdot \nabla) \mathbf{V}\right]=-\nabla p+\mu \nabla^{2} \mathbf{V}+\left[C\left(\rho_{p}-\rho_{f 0}\right)+\rho_{f 0}\left(1-\beta\left(T-T_{\mathcal{C}}\right)\left(1-C_{0}\right)\right)\right] \mathbf{g}
$$

Governing Equations (2), (4)-(6) can be written using the stream function $\bar{\psi}\left(u=\frac{\partial \bar{\psi}}{\partial \bar{y}}, \quad v=-\frac{\partial \bar{\psi}}{\partial \bar{x}}\right)$ and vorticity $\bar{\omega}\left(\bar{\omega}=\frac{\partial v}{\partial \bar{x}}-\frac{\partial u}{\partial \bar{y}}\right)$ in Cartesian coordinates $\bar{x}$ and $\bar{y}$ as

$$
\begin{aligned}
& \frac{\partial^{2} \bar{\psi}}{\partial \bar{x}^{2}}+\frac{\partial^{2} \bar{\psi}}{\partial \bar{y}^{2}}=-\bar{\omega} \\
& \frac{\partial \bar{\omega}}{\partial t}+\frac{\partial \bar{\psi}}{\partial \bar{y}} \frac{\partial \bar{\omega}}{\partial \bar{x}}-\frac{\partial \bar{\psi}}{\partial \bar{x}} \frac{\partial \bar{\omega}}{\partial \bar{y}}=v\left(\frac{\partial^{2} \bar{\omega}}{\partial \bar{x}^{2}}+\frac{\partial^{2} \bar{\omega}}{\partial \bar{y}^{2}}\right)+\left(1-C_{0}\right) \beta g \frac{\partial T}{\partial \bar{x}}-g \frac{\rho_{p}-\rho_{f 0}}{\rho_{f 0}} \frac{\partial C}{\partial \bar{x}} \\
& \frac{\partial T}{\partial t}+\frac{\partial \bar{\psi}}{\partial \bar{y}} \frac{\partial T}{\partial \bar{x}}-\frac{\partial \bar{\psi}}{\partial \bar{x}} \frac{\partial T}{\partial \bar{y}}=\alpha\left(\frac{\partial^{2} T}{\partial \bar{x}^{2}}+\frac{\partial^{2} T}{\partial \bar{y}^{2}}\right)+ \\
& +\delta\left\{D_{B}\left(\frac{\partial C}{\partial \bar{x}} \frac{\partial T}{\partial \bar{x}}+\frac{\partial C}{\partial \bar{y}} \frac{\partial T}{\partial \bar{y}}\right)+\frac{D_{T}}{T_{C}}\left[\left(\frac{\partial T}{\partial \bar{x}}\right)^{2}+\left(\frac{\partial T}{\partial \bar{y}}\right)^{2}\right]\right\} \\
& \frac{\partial C}{\partial t}+\frac{\partial \bar{\psi}}{\partial \bar{y}} \frac{\partial C}{\partial \bar{x}}-\frac{\partial \bar{\psi}}{\partial \bar{x}} \frac{\partial C}{\partial \bar{y}}=D_{B}\left(\frac{\partial^{2} C}{\partial \bar{x}^{2}}+\frac{\partial^{2} C}{\partial \bar{y}^{2}}\right)+\left(\frac{D_{T}}{T_{C}}\right)\left(\frac{\partial^{2} T}{\partial \bar{x}^{2}}+\frac{\partial^{2} T}{\partial \bar{y}^{2}}\right)
\end{aligned}
$$

Introducing the following dimensionless variables:

$$
\begin{aligned}
\tau=t \sqrt{g \beta\left(1-C_{0}\right) \Delta T / L}, \quad x=\bar{x} / L, & y=\bar{y} / L, \quad \psi=\bar{\psi} / \sqrt{g \beta\left(1-C_{0}\right) \Delta T L^{3}}, \\
\omega=\bar{\omega} \sqrt{L /\left(g \beta\left(1-C_{0}\right) \Delta T\right)}, & \theta=\left(T-T_{c}\right) / \Delta T, \quad \phi=C / C_{0}
\end{aligned}
$$

where $\Delta T=T_{h}-T_{c}$ and substituting (11) into Equations (7)-(10), we obtain:

$$
\frac{\partial^{2} \psi}{\partial x^{2}}+\frac{\partial^{2} \psi}{\partial y^{2}}=-\omega
$$




$$
\begin{gathered}
\frac{\partial \omega}{\partial \tau}+\frac{\partial \psi}{\partial y} \frac{\partial \omega}{\partial x}-\frac{\partial \psi}{\partial x} \frac{\partial \omega}{\partial y}=\sqrt{\frac{P r}{R a}}\left(\frac{\partial^{2} \omega}{\partial x^{2}}+\frac{\partial^{2} \omega}{\partial y^{2}}\right)+\frac{\partial \theta}{\partial x}-N r \frac{\partial \phi}{\partial x} \\
\frac{\partial \theta}{\partial \tau}+\frac{\partial \psi}{\partial y} \frac{\partial \theta}{\partial x}-\frac{\partial \psi}{\partial x} \frac{\partial \theta}{\partial y}=\frac{1}{\sqrt{R a \cdot P r}}\left(\frac{\partial^{2} \theta}{\partial x^{2}}+\frac{\partial^{2} \theta}{\partial y^{2}}\right)+ \\
+\frac{N b}{\sqrt{R a \cdot P r}}\left(\frac{\partial \phi}{\partial x} \frac{\partial \theta}{\partial x}+\frac{\partial \phi}{\partial y} \frac{\partial \theta}{\partial y}\right)+\frac{N t}{\sqrt{R a \cdot P r}}\left[\left(\frac{\partial \theta}{\partial x}\right)^{2}+\left(\frac{\partial \theta}{\partial y}\right)^{2}\right] \\
\frac{\partial \phi}{\partial \tau}+\frac{\partial \psi}{\partial y} \frac{\partial \phi}{\partial x}-\frac{\partial \psi}{\partial x} \frac{\partial \phi}{\partial y}=\frac{1}{L e \sqrt{R a \cdot P r}}\left[\frac{\partial^{2} \phi}{\partial x^{2}}+\frac{\partial^{2} \phi}{\partial y^{2}}\right]+\frac{N t}{L e \cdot N b \cdot \sqrt{R a \cdot P r}}\left[\frac{\partial^{2} \theta}{\partial x^{2}}+\frac{\partial^{2} \theta}{\partial y^{2}}\right]
\end{gathered}
$$

Here $\psi$ is the dimensionless stream function, $\omega$ is the dimensionless vorticity, $x$ and $y$ are the dimensionless coordinates, $\tau$ is the dimensionless time, $\theta$ is the dimensionless temperature, $\phi$ is the rescaled nanoparticles volume fraction.

Corresponding boundary conditions of these Equations (12)-(15) are given by:

$$
\begin{array}{ll}
\psi=0, \quad \omega=-\frac{\partial^{2} \psi}{\partial x^{2}}, & \theta=1+\varepsilon[1-\cos (2 \pi \kappa y)], \quad \widetilde{\mathfrak{j}}_{p}=0 \quad\left(\text { or } \quad N b \frac{\partial \phi}{\partial x}+N t \frac{\partial \theta}{\partial x}=0\right) \text { at left wall; } \\
\psi=0, & \omega=-\frac{\partial^{2} \psi}{\partial x^{2}}, \quad \theta=0, \quad \widetilde{\mathbf{j}}_{p}=0 \quad\left(\text { or } \quad N b \frac{\partial \phi}{\partial x}+N t \frac{\partial \theta}{\partial x}=0\right) \text { at right wall; } \\
\psi=0, \quad \omega=-\frac{\partial^{2} \psi}{\partial y^{2}}, & \frac{\partial \theta}{\partial y}=0, \quad \frac{\partial \phi}{\partial y}=0 \text { at bottom and top walls. }
\end{array}
$$

The involved parameters in Equations (12)-(16) are: the Rayleigh number, $R a=\left(1-C_{0}\right) g \beta \Delta T L^{3} /(v \alpha)$, the Prandtl number, $\operatorname{Pr}=v / \alpha$ and the dimensionless nanoparticles mass flux, $\widetilde{\mathbf{j}}_{p}$. Further, the four parameters $N r, N b, N t$ and Le denote the buoyancy ratio parameter, the Brownian motion parameter, the thermophoresis parameter and the Lewis number, respectively, which are defined as:

$$
N r=\frac{\left(\rho_{p}-\rho_{f 0}\right) C_{0}}{\rho_{f 0} \beta \Delta T\left(1-C_{0}\right)}, \quad N b=\frac{\delta D_{B} C_{0}}{\alpha}, \quad N t=\frac{\delta D_{T} \Delta T}{\alpha T_{c}}, \quad L e=\frac{\alpha}{D_{B}}
$$

The local and average Nusselt numbers along the left vertical wall can be defined as:

$$
N u=-\left.\frac{\partial \theta}{\partial x}\right|_{x=0}, N u_{a v g}=\int N u d y
$$

The definitions for local and average Sherwood numbers are similar to Nusselt numbers for left vertical wall taking into account the used boundary conditions, namely, $\frac{\partial \phi}{\partial x}=-\frac{N t}{N b} \frac{\partial \theta}{\partial x}$ or $S h=-\left.\frac{\partial \phi}{\partial x}\right|_{x=0}=\left.\frac{N t}{N b} \frac{\partial \theta}{\partial x}\right|_{x=0}=-\frac{N t}{N b} N u$.

The existence of some irreversible phenomena, such as, viscous dissipation and heat and mass transfer are measured by the entropy generation. The dimensional local entropy generation $\bar{S}_{g e n}$ is defined in the following form (see Sheremet et al. [27,28] and Bondareva et al. [29]):

$$
\begin{aligned}
& \bar{S}_{\text {gen }}=\frac{k_{f}}{T_{0}^{2}}\left[\left(\frac{\partial T}{\partial \bar{x}}\right)^{2}+\left(\frac{\partial T}{\partial \bar{y}}\right)^{2}\right]+\frac{\mu_{f}}{T_{0}}\left[2\left(\frac{\partial u}{\partial \bar{x}}\right)^{2}+2\left(\frac{\partial v}{\partial \bar{y}}\right)^{2}+\left(\frac{\partial u}{\partial \bar{y}}+\frac{\partial v}{\partial \bar{x}}\right)^{2}\right]+ \\
& +\frac{R D_{B}}{C_{0}}\left[\left(\frac{\partial C}{\partial \bar{x}}\right)^{2}+\left(\frac{\partial C}{\partial \bar{y}}\right)^{2}\right]+\frac{R D_{B}}{T_{0}}\left[\left(\frac{\partial C}{\partial \bar{x}}\right)\left(\frac{\partial T}{\partial \bar{x}}\right)+\left(\frac{\partial C}{\partial \bar{y}}\right)\left(\frac{\partial T}{\partial \bar{y}}\right)\right]
\end{aligned}
$$

where $T_{0}=\frac{T_{c}+T_{h}}{2}$ and $R$ is the universal gas constant.

Equation (19) includes four terms illustrating the local entropy generation due to the heat transfer $\left(\bar{S}_{g e n, h t}\right)$ (first term), the local entropy generation due to fluid friction $\left(\bar{S}_{g e n, f f}\right)$ (second term) and the local entropy generation due to mass transfer $\left(\bar{S}_{g e n, m t}\right)$ (third and fourth term). 
The dimensionless local entropy generation $S_{g e n}$ can be obtained as:

$$
\begin{aligned}
& S_{g e n}=\bar{S}_{g e n} \frac{T_{0}^{2} L^{2}}{k_{f}\left(T_{h}-T_{c}\right)^{2}}=\left[\left(\frac{\partial \theta}{\partial x}\right)^{2}+\left(\frac{\partial \theta}{\partial y}\right)^{2}\right]+\chi_{1}\left[4\left(\frac{\partial^{2} \psi}{\partial x \partial y}\right)^{2}+\left(\frac{\partial^{2} \psi}{\partial y^{2}}-\frac{\partial^{2} \psi}{\partial x^{2}}\right)^{2}\right]+ \\
& +\chi_{2}\left[\left(\frac{\partial \phi}{\partial x}\right)^{2}+\left(\frac{\partial \phi}{\partial y}\right)^{2}\right]+\chi_{3}\left[\left(\frac{\partial \phi}{\partial x}\right)\left(\frac{\partial \theta}{\partial x}\right)+\left(\frac{\partial \phi}{\partial y}\right)\left(\frac{\partial \theta}{\partial y}\right)\right]=S_{g e n, h t}+S_{g e n, f f}+S_{g e n, m t}
\end{aligned}
$$

In Equation (20), $\chi_{1}, \chi_{2}, \chi_{3}$ are the irreversibility factors. Those are defined as follows:

$$
\chi_{1}=\frac{\mu_{f} T_{0}}{k_{f}}\left(\frac{g \beta_{f} L}{T_{h}-T_{c}}\right), \chi_{2}=\frac{R D_{B} C_{0} T_{0}^{2}}{k_{f}\left(T_{h}-T_{c}\right)^{2}}, \chi_{3}=\frac{R D_{B} C_{0} T_{0}}{k_{f}\left(T_{h}-T_{c}\right)}
$$

The integration of Equation (20) in the entire computational domain gives the dimensionless average entropy generation, $S_{\text {gen, avg }}$, expressed as follows:

$$
S_{g e n, a v g}=\frac{1}{\vartheta} \int S_{g e n} d \vartheta=S_{g e n, h t, a v g}+S_{g e n, f f, a v g}+S_{g e n, m t, a v g}
$$

Further, the Bejan number $B e$ is a parameter reflecting the importance of heat transfer irreversibility in the domain and is defined as:

$$
B e=\frac{S_{g e n, h t}}{S_{g e n, h t}+S_{g e n, f f}+S_{g e n, m t}}
$$

The relative global dominance of heat transfer irreversibility is predicted by $B e_{a v g}$ (average Bejan number) which can be defined as:

$$
B e_{a v g}=\frac{S_{g e n, h t, a v g}}{S_{g e n, h t, a v g}+S_{g e n, f f, a v g}+S_{g e n, m t, a v g}}
$$

\section{Numerical Method and Validation}

The unsteady partial differential Equations (12)-(15) with corresponding boundary conditions (16) were solved using the finite difference method (see Shenoy et al. [5], Sheremet and Pop [17,18], Sheremet et al. $[27,28])$. The solution of these equations is marched in time until the steady-state flow is obtained. The convective and diffusive terms are approximated by the second-order discretizations. The transient equations were solved on the basis of Samarskii locally one-dimensional scheme. The linear discretized equations were solved by Thomas algorithm. The Poisson equation for the stream function was discretized by means of the five-point difference scheme on the basis of central differences for the second derivatives. The obtained linear discretized equation was solved by the successive over relaxation method. Optimum value of the relaxation parameter was chosen on the basis of computing experiments. The computation is finished when the residuals for the stream function get below $10^{-7}$.

The performance of sinusoidal heating part of the model was compared with the results reported by Deng and Chang [46], and Sivasankaran and Bhuvaneswari [47] for the steady-state natural convection in a square cavity with sinusoidal heating at vertical walls filled with a regular fluid. Figures 2-4 show a good agreement between the obtained streamlines and isotherms for different Rayleigh numbers and the numerical data of Deng and Chang [46] (see Figures 3a,b and 11c in [46]), and Sivasankaran and Bhuvaneswari [47] (see Figure 1b in [47]). This give us the confidence that the proposed numerical scheme is correct and works efficiently. 
$\Psi$

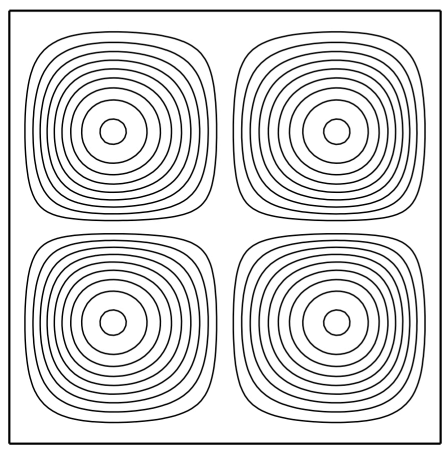

$\Theta$

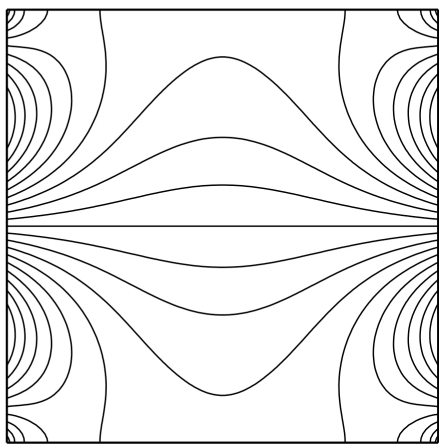

Figure 2. Obtained streamlines $\Psi$ and isotherms $\Theta$ at $R a=10^{3}$ and phase deviation $\varphi=0$.

$\Psi$

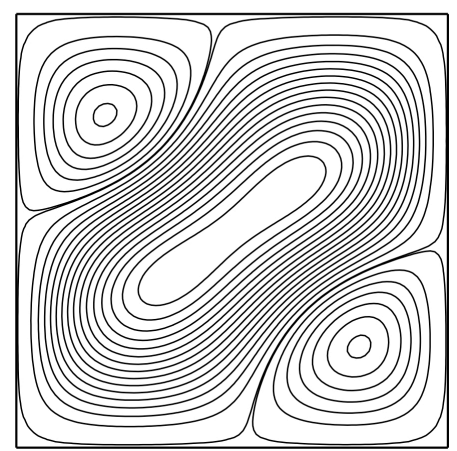

$\Theta$

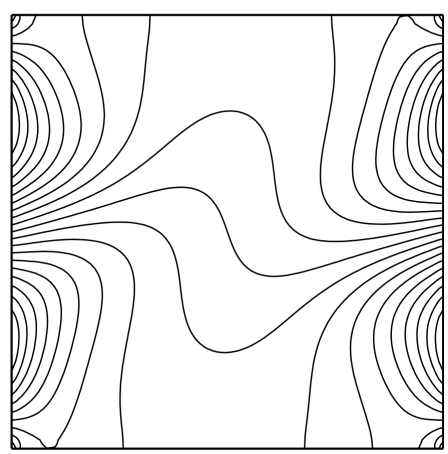

Figure 3. Obtained streamlines $\Psi$ and isotherms $\Theta$ at $R a=10^{4}$ and phase deviation $\varphi=0$.

$\Psi$

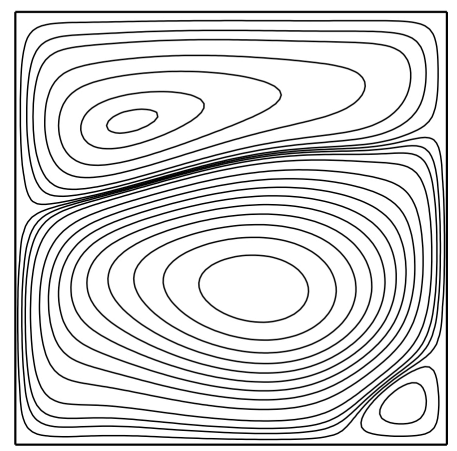

$\Theta$

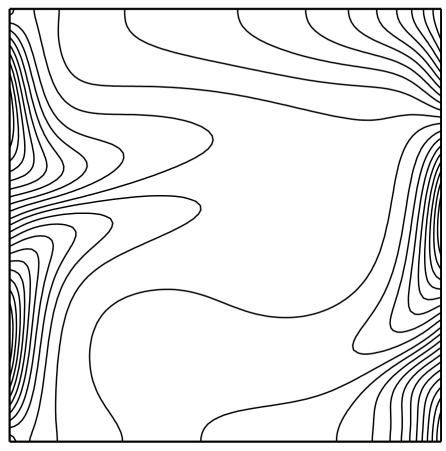

Figure 4. Obtained streamlines $\Psi$ and isotherms $\Theta$ at $R a=10^{5}$ and phase deviation $\varphi=\pi / 2$.

The grid independent solution was performed by preparing the solution for steady-state natural convection in a square cavity with variable temperature distribution on left vertical wall filled with a nanofluid for $R a=1000, P r=7.0, L e=1000, N r=N b=N t=0.1, \varepsilon=1, \kappa=1, \chi_{1}=0.0001, \chi_{2}=0.5, \chi_{3}=0.01$. Values of the irreversibility factors are the same with those used in the paper by Magherbi et al. [48]. Six cases of the uniform grid are tested: a grid of $100 \times 100$ points, a grid of $150 \times 150$ points, a grid of $200 \times 200$, a grid of $250 \times 250$ points, a grid of $300 \times 300$ points, and a grid of $400 \times 400$ points Table 1 shows the effect of the mesh parameters on the average Nusselt number on the hot wall. On the basis of the conducted verifications the uniform grid of $200 \times 200$ points has been selected for the following analysis. 
Table 1. Variations of the average Nusselt number of left wall with the uniform grids.

\begin{tabular}{|c|c|c|c|}
\hline Uniform Grids & $N u_{a v g}$ & $\Delta=\frac{\left|N u_{i \times j}^{a v g}-N u_{200 \times 200}^{a v g}\right|}{N u_{i \times j}^{a v g}}$ & $\times 100 \%$ \\
\hline $100 \times 100$ & 4.60418 & 0.35 & \\
\hline $150 \times 150$ & 4.61435 & 0.13 & \\
\hline $200 \times 200$ & 4.62035 & - & \\
\hline $250 \times 250$ & 4.62548 & 0.11 & \\
\hline $300 \times 300$ & 4.62991 & 0.21 & \\
\hline $400 \times 400$ & 4.63827 & 0.39 & \\
\hline
\end{tabular}

\section{Results and Discussion}

In this section, we discuss the results obtained by numerical simulation of natural convection and entropy generation in a square cavity filled with a water based nanofluid considering a variable temperature along the left vertical wall under the effects of Brownian diffusion and thermophoresis. Analysis has been performed for the following values of the governing parameters: Rayleigh number $\left(R a=10^{3}-10^{5}\right)$, Prandtl number $(P r=7.0)$, Lewis number $(L e=1000)$, buoyancy-ratio parameter $(N r=0.1)$, Brownian motion parameter $(N b=0.1)$, thermophoresis parameter $(N t=0.1)$, amplitude of the variable hot-wall temperature $(\varepsilon=0.0-1.0)$, wave number of the hot-wall temperature $(\kappa=0.0-5.0)$. Particular efforts have been focused on the effects of these parameters on the fluid flow, heat transfer and entropy generation inside the cavity. Streamlines, isotherms, nanoparticles volume fraction, entropy generation parameters as well as the average Nusselt number, fluid flow rate, average Bejan number and average entropy generation for different values of the key parameters mentioned above are illustrated in Figures 5-14.
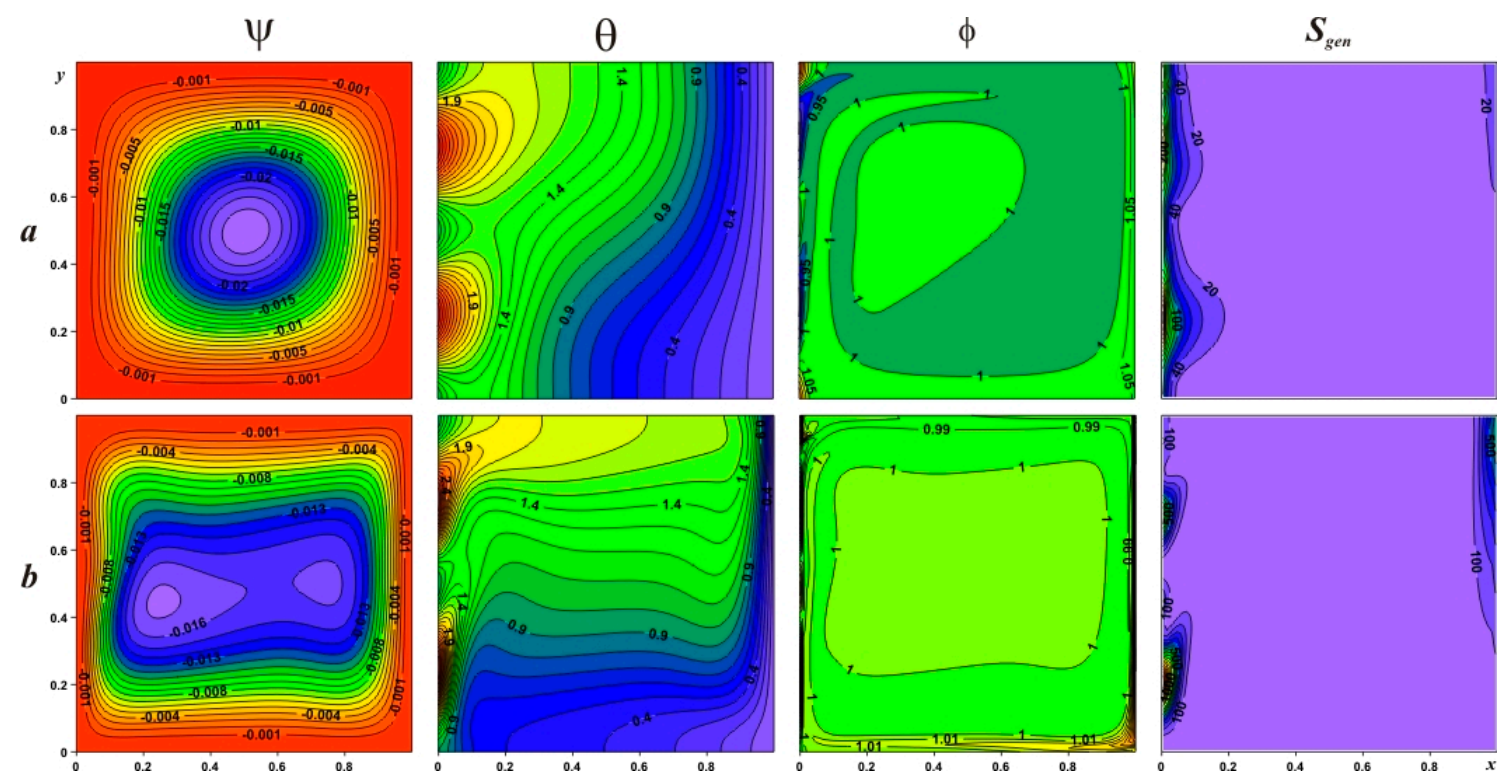

Figure 5. Streamlines $\psi$, isotherms $\theta$, nanoparticles volume fraction $\phi$ and total entropy generation $S_{\text {gen }}$ for $\varepsilon=1.0, \kappa=2.0$ : (a) $R a=10^{3}$, (b) $R a=10^{5}$.

Figure 5 presents streamlines, isotherms, nanoparticles volume fraction and local entropy generation within the cavity for different values of Rayleigh number and for $\varepsilon=1.0, \kappa=2.0$. In the case of $R a=10^{3}$ (Figure 5a) one convective cell is formed inside the cavity illustrating an ascending flow near the left hot wall and descending flows close to the right cold wall. Distribution of temperature along the left wall has two local maximum points due to the value of the wave number, $\kappa=2.0$. At the same time, the low value of Rayleigh number shows that heat conduction dominates near the 
left wall, the isotherms being uniformly distributed in these zones. Domination of heat conduction reflects a significant effect of thermophoresis inside the cavity. Therefore, one can find non-uniform distribution of nanoparticles inside the cavity, where significant reduction of $\phi$ occurs along the left hot wall and a growth of $\phi$ occurs along the right cold wall. The distribution of local entropy generation illustrates an intensification of $S_{\text {gen }}$ along the left wall due to significant heat transfer part (high values of temperature gradient along this wall).

An increase in the Rayleigh number (Figure $5 b$ ) leads to a formation of a convective cell with two cores similar to the case of the clear fluid (Vahl Davis [7]) but here these cores are displaced due to the additional effects of Brownian diffusion and thermophoresis. The distribution of the temperature reflects the formation of a stratified zone in the central part of the cavity. Intensified convective flow and heat transfer illustrate non-uniform temperature distribution in heated zones along the left vertical wall. Distribution of nanoparticles is more uniform in comparison with the case of $R a=10^{3}$. At the same time, $S_{g e n}$ increases significantly along the vertical walls due to intensification of the convective flow and as a result a growth of temperature gradient appears.

Figure 6 shows profiles of local Nusselt number along the left vertical wall for different values of the Rayleigh number. Regardless of the Rayleigh number value, two local maxima of $\mathrm{Nu}$ are along the wall in the heated zones. An increase in $R a$ leads to significant growth of $N u$ in these heated zones. At the same time, location of maxima goes weakly along the negative $y$-coordinate. It should be noted, that bottom local maximum is a global maximum due to an interaction of hot flow from the left heated zone and cold flow from the right cooled wall.

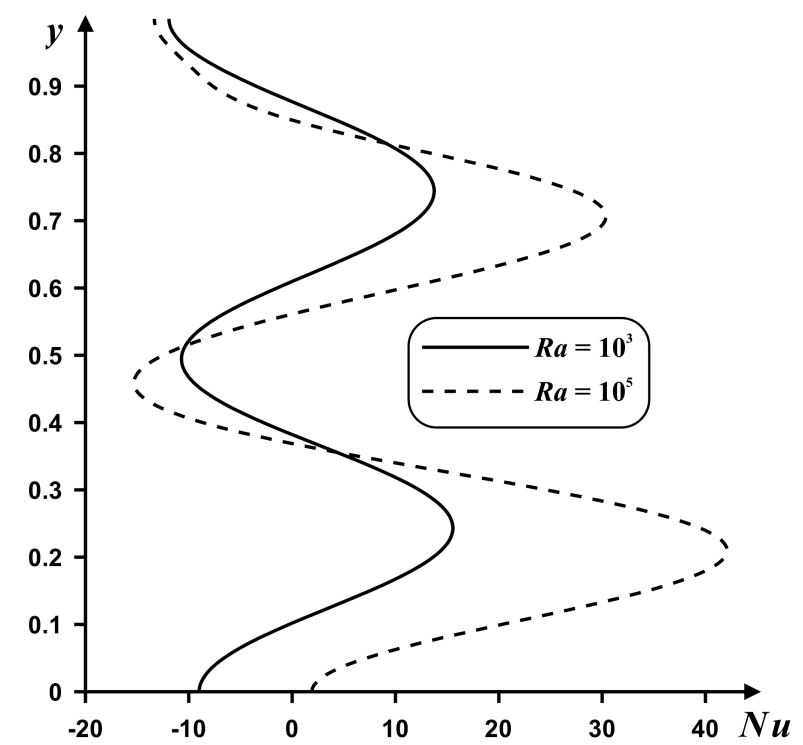

Figure 6. Profiles of local Nusselt number along left vertical wall for $\varepsilon=1.0, \kappa=2.0$ and different Rayleigh numbers.

Distributions of local parameters inside the cavity for $R a=10^{3}, \kappa=2.0$ and different values of left wall temperature amplitude are presented in Figure 7. For the considered range of $\varepsilon$ one can find non-significant changes in streamlines, while other parameters change significantly. High values of amplitude characterize more significant heating of the cavity due to an increase in temperature along the left vertical wall. Such heating leads to non-uniform distributions of nanoparticles inside the cavity and local entropy generation increases within the enclosure, mainly, close to the vertical walls. 

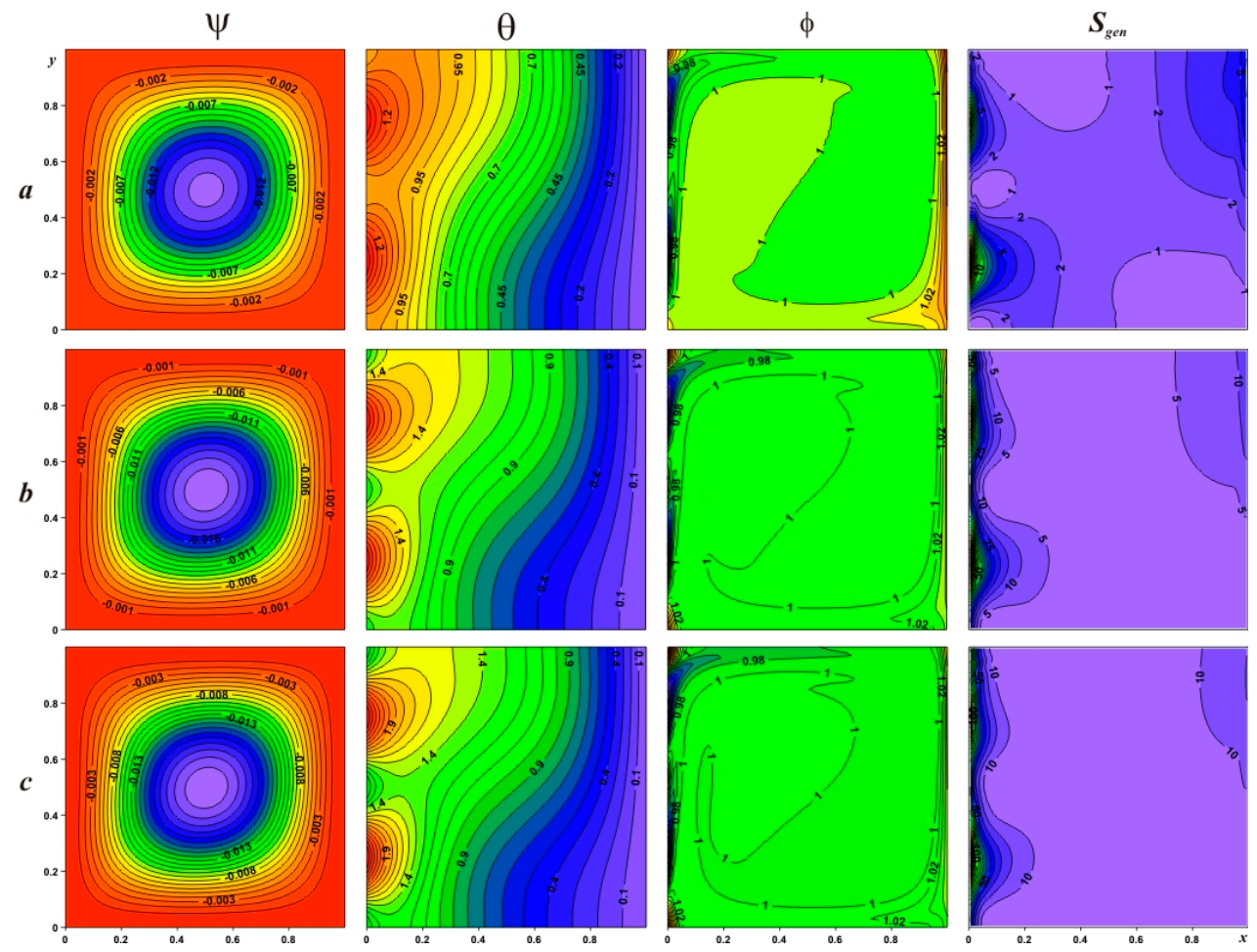

Figure 7. Streamlines $\psi$, isotherms $\theta$, nanoparticles volume fraction $\phi$ and total entropy generation $S_{\text {gen }}$ for $R a=10^{3}, \kappa=2.0:(\mathbf{a}) \varepsilon=0.2,(\mathbf{b}) \varepsilon=0.6,(\mathbf{c}) \varepsilon=0.8$.

Profiles of local Nusselt number along the left vertical wall are shown in Figure 8. An increase in $\varepsilon$ leads to a growth of local maxima and minima of $N u$, as a result, average Nusselt number at this wall is an increasing function of $\varepsilon$ (see Figure 9a). At the same time, a rise of Rayleigh number also leads to a growth of average Nusselt number. It is worth noting that an increase in $N u_{\text {avg }}$ with $\varepsilon$ is more significant for high values of Rayleigh number. One can find also that fluid flow rate is an increasing function of wall temperature amplitude and Rayleigh number. Intensity of convective flow raises more significant for high values of Rayleigh number (see Figure 9b).

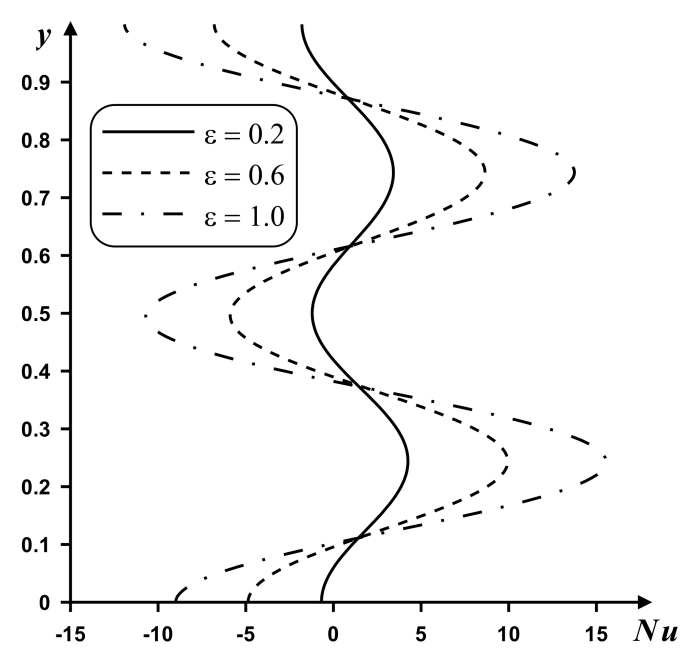

Figure 8. Profiles of local Nusselt number along left vertical wall for $R a=10^{3}, \kappa=2.0$ and different values of amplitude. 


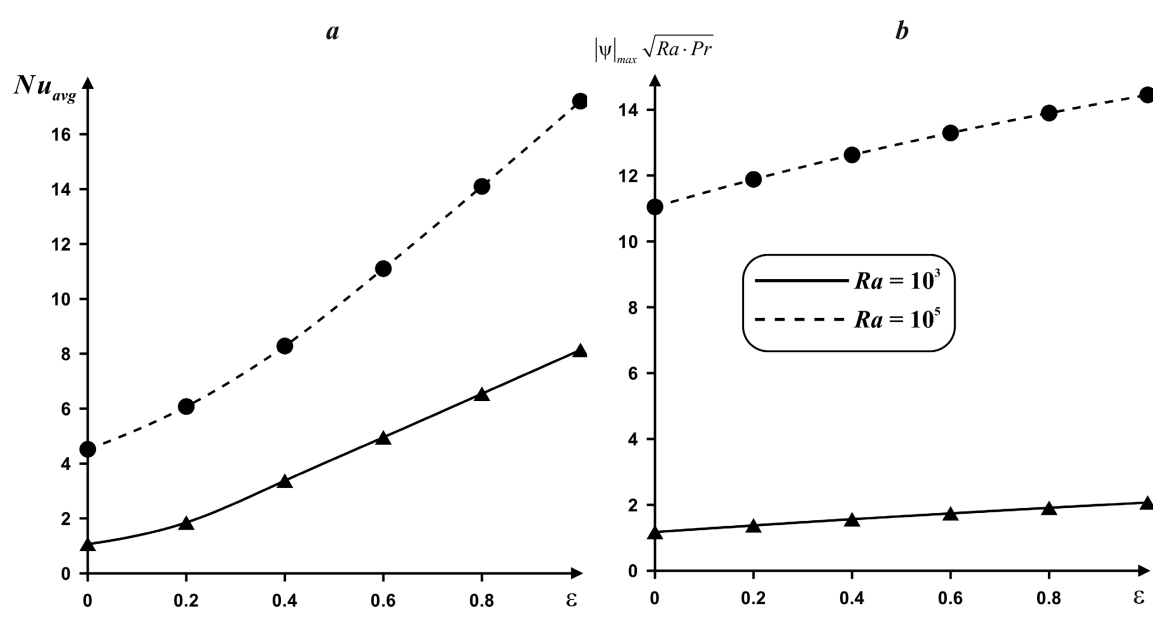

Figure 9. Variations of average Nusselt number (a) and fluid flow rate (b) for $\kappa=2.0$ and different values of amplitude $\varepsilon$ and Rayleigh number.

The effects of $R a$ and $\varepsilon$ on average Bejan number and average entropy generation are presented in Figure 10. Average entropy generation is an increasing function of $R a$ and $\varepsilon$, while $B e_{a v g}$ decreases with $\varepsilon$ for low value of Rayleigh number $\left(R a=10^{3}\right)$ and increases with $\varepsilon$ for high value of Rayleigh number $\left(R a=10^{5}\right)$. Such behavior has been mentioned above, where high values of $R a$ reflect more intensive convective flow and heat transfer with high values of temperature gradient. The behavior of average entropy generation is similar to average Nusselt number in the case of more significant growth for high $R a$.

Effect of wave number on streamlines, isotherms, isoconcentrations and isolines of local entropy generation is presented in Figure 11 for $R a=10^{3}, \varepsilon=1$.0. It should be noted that a growth of $\kappa$ illustrates an increase in heated zones along the left vertical wall that is presented in distributions of temperature. An increase in wave number does not lead to significant modifications of streamlines, while temperature, nanoparticles volume fraction and entropy generation fields change significantly. A growth of $\kappa$ leads to more uniform heating of the left vertical wall and one can find more significant heating near this wall. Nanoparticles isoconcentrations become more uniform for high values of wave number. Local entropy generation increases also with $\kappa$ and significant growth occurs close the left vertical wall.

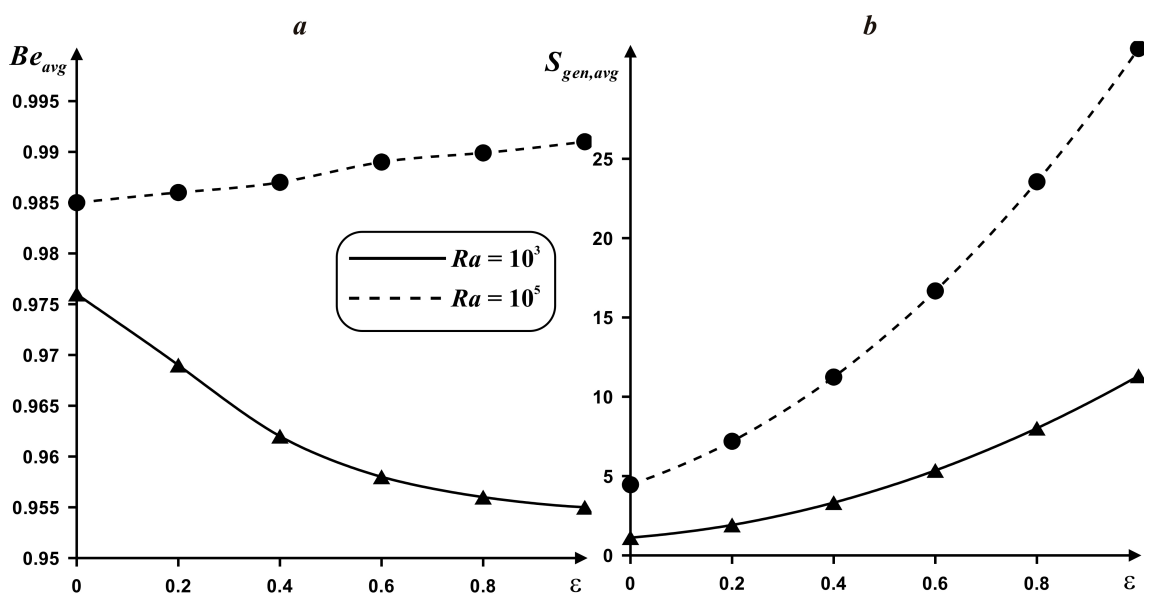

Figure 10. Variations of average Bejan number (a) and average entropy generation (b) for $\kappa=2.0$ and different values of amplitude $\varepsilon$ and Rayleigh number. 

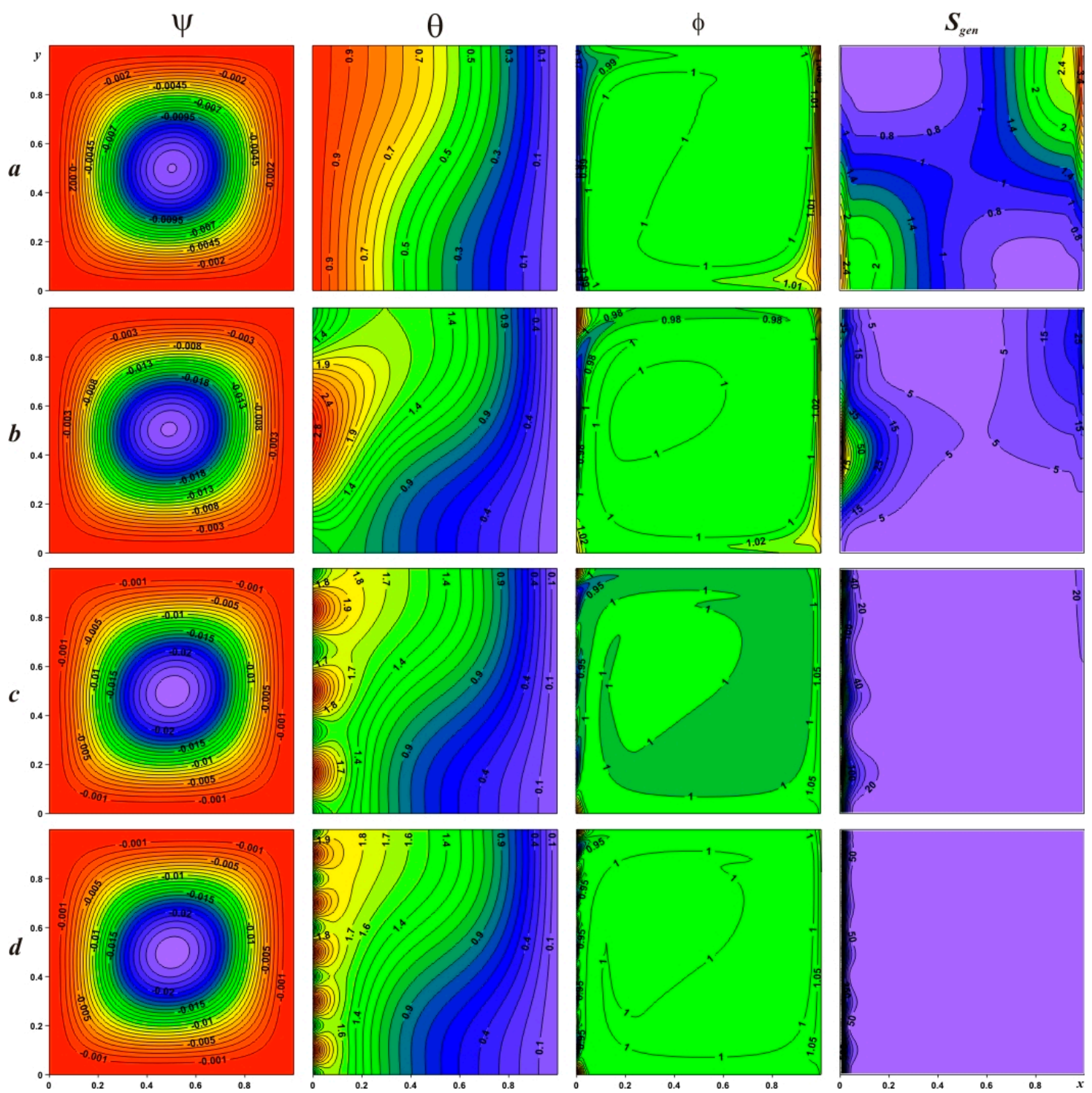

Figure 11. Streamlines $\psi$, isotherms $\theta$, nanoparticles volume fraction $\phi$ and total entropy generation $S_{\text {gen }}$ for $R a=10^{3}, \varepsilon=1.0$ : (a) $\kappa=0.0$, (b) $\kappa=1.0$, (c) $\kappa=3.0$, (d) $\kappa=5.0$.

Profiles of local Nusselt number for different values of wave number are shown in Figure 12. An increase in $\kappa$ leads not only to a rise of number of local maximum but also to a growth of amplitude of local Nusselt number. As a result, we have a significant increase in average Nusselt number at the left vertical wall (see Figure 13a). Nanofluid flow rate increases also with $\kappa$, but for $\kappa>3$ in considered range of Rayleigh number, the fluid flow rate is near constant. Local maximum in $|\psi|_{\max }$ is formed at greater value of wave number with a growth of Rayleigh number. 


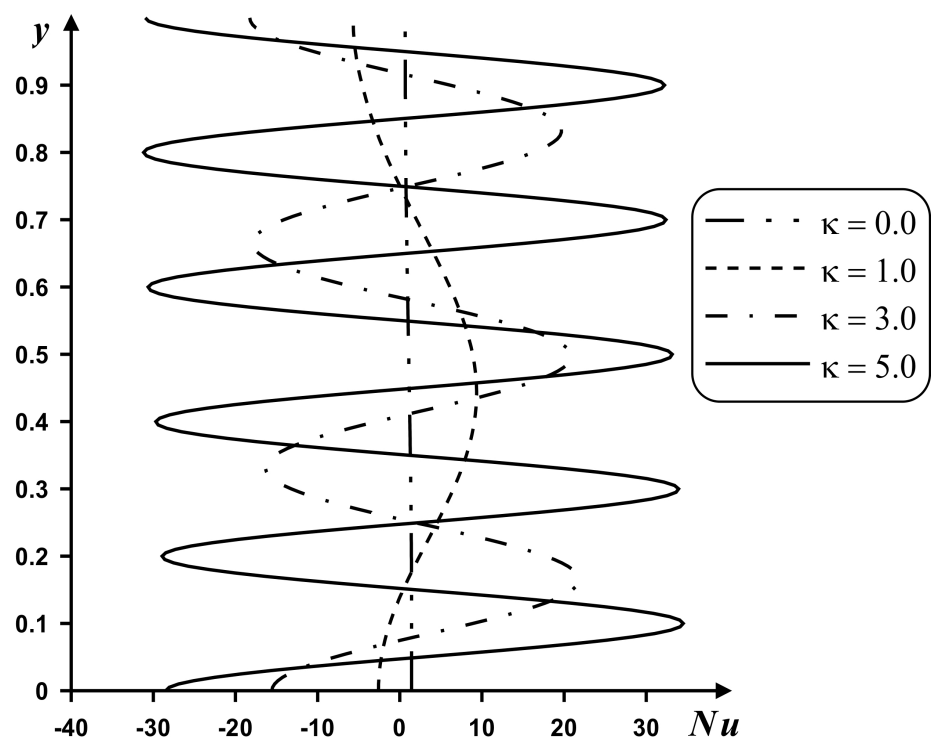

Figure 12. Profiles of local Nusselt number along left vertical wall for $R a=10^{3}, \varepsilon=1.0$ and different values of wave number.

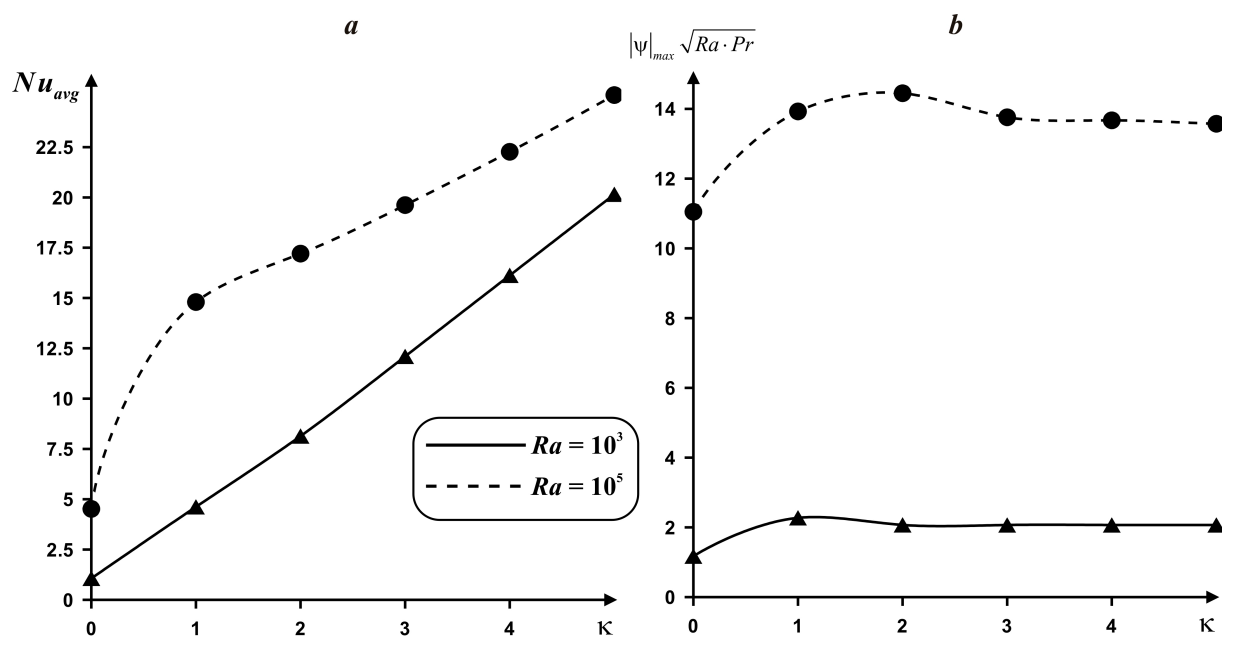

Figure 13. Variations of average Nusselt number (a) and fluid flow rate (b) for $\varepsilon=1.0$ and different values of wave number and Rayleigh number.

Behavior of the average Bejan number and the average entropy generation shown in Figure 14 is similar to behavior presented in Figure 10. It should be noted that low Rayleigh number $\left(R a=10^{3}\right)$ illustrates a decrease in average Bejan number with wave number due to a reduction of the heat transfer irreversibility for low intesive flow and heat transfer in comaprison with fluid friction irreversibility and mass transfer irreversibility. At the same time, the average entropy generation significantly increases with transition between constant temperature $(\kappa=0)$ and variable temperature distribution $(\kappa=1)$ for $R a=10^{5}$ due to intesification of convective flow. Average Bejan number for high Rayleigh number characterizes a weak changes owing to significant role of heat transfer irreversibility. 


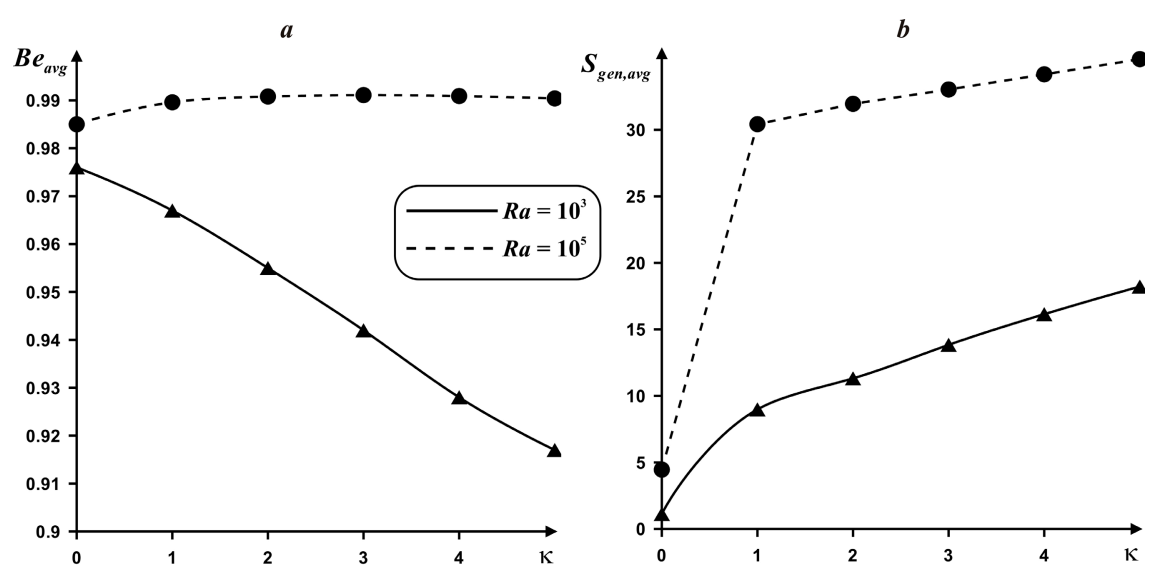

Figure 14. Variations of average Bejan number (a) and average entropy generation (b) for $\varepsilon=1.0$ and different values of wavy number and Rayleigh number.

Obtained results have been used to obtain the correlations for the average Nusselt number on the basis of a least-square regression technique in a wide range of governing parameters $0.2 \leq \varepsilon \leq 1.0$, $1 \leq \kappa \leq 5$ for $R a=10^{3}$ and $R a=10^{5}$ in the following form:

$$
\left.\begin{array}{c}
N u_{\text {avg }}=4.798 \cdot \kappa^{0.846} \cdot \varepsilon^{0.915} \text { for } R a=10^{3} \\
N u_{\text {avg }}=15.047 \cdot \kappa^{0.213} \cdot \varepsilon^{0.703} \text { for } R a=10^{5}
\end{array}\right\}
$$

\section{Conclusions}

Natural convection combined with entropy generation within a square cavity filled with a water based nanofluid under the effects of left vertical wall variable temperature, Brownian diffusion and thermophoresis has been analyzed numerically using finite difference method of the second order accuracy. The developed numerical method has been verified using the grid independence test and numerical data of other authors. A study of the effects of Rayleigh number, variable temperature amplitude and wave number on nanofluid flow, heat and mass transfer has been carried out. It has been found that an increase in the Rayleigh number leads to an intensification of entropy generation along the vertical walls, distribution of nanoparticles become more uniform and all average considered parameters increase with $R a$. An increase in variable temperature amplitude leads to an intensification of convective flow and heat transfer, while entropy generation increases also and average Bejan number increase for high values of Rayleigh number and decreases for low value of Rayleigh number. Effect of wave number on average considered parameters is similar to the effect of temperature amplitude on these parameters. It should be noted that the obtained results can be used for analysis of solar energy collection and cooling of electronic components.

Acknowledgments: This work of Mikhail A. Sheremet was supported by the Grants Council (under the President of the Russian Federation), Grant No. MD-2819.2017.8. Also, the authors wish to express their thanks to the very competent Reviewers for the very good comments and suggestions.

Author Contributions: All authors proposed and obtained the mathematical model. Mikhail A. Sheremet proposed the numerical model and solved the equations. All authors analyzed and discussed the obtained data. All authors have read and approved the final manuscript.

Conflicts of Interest: The authors declare no conflict of interest.

\section{References}

1. Minkowycz, W.J.; Sparrow, E.M.; Schneider, G.E.; Pletcher, R.H. Handbook of Numerical Heat Transfer; Wiley: New York, NY, USA, 1988.

2. Yang, K.T. Natural Convection in Enclosure; Wiley: New York, NY, USA, 1987. 
3. Pop, I.; Ingham, D.B. Convective Heat Transfer: Mathematical and Computational Modelling of Viscous Fluids and Porous Media; Pergamon Press: Oxford, UK, 2001.

4. Bejan, A. Convective Heat Transfer, 4th ed.; Wiley: New York, NY, USA, 2013.

5. Shenoy, A.; Sheremet, M.; Pop, I. Convective Flow and Heat Transfer from Wavy Surfaces: Viscous Fluids, Porous Media and Nanofluids; CRC Press: Boca Raton, FL, USA, 2016.

6. Saeid, N.H.; Yaacob, Y. Natural convection in a square cavity with spatial side-wall temperature variation. Numer. Heat Transf. Part A 2006, 49, 683-697. [CrossRef]

7. De Vahl Davis, G. Natural convection of air in a square cavity: A bench mark numerical solution. Int. J. Numer. Methods Fluids 1983, 3, 249-264. [CrossRef]

8. Ostrach, S. Natural convection in enclosures. ASME J. Heat Transf. 1988, 110, 1175-1190. [CrossRef]

9. Hortmann, M.; Peric, M.; Scheuerer, M.G. Finite volume multigrid prediction of laminar natural convection: Bench-mark solution. Int. J. Numer. Methods Fluids 1990, 11, 189-207. [CrossRef]

10. Barakos, G.; Mitsoulis, E.; Assimacopoulos, D. Natural convection flow in a square cavity revisited: Laminar and turbulent models with wall functions. Int. J. Numer. Methods Fluids 1994, 18, 695-719. [CrossRef]

11. Fu, W.S.; Tseng, C.C.; Chen, Y.C. Natural convection in an enclosure with nonuniform wall temperature. Int. Commun. Heat Mass Transf. 1994, 21, 819-828. [CrossRef]

12. Xia, Q.; Yang, K.T.; Mukutmoni, D. Effect of imposed wall temperature oscillations on the stability of natural convection in a square enclosure. J. Heat Transf. 1995, 117, 113-120. [CrossRef]

13. Lakhal, E.K.; Hasnaoui, M.; Vasseur, P.; Bilgen, E. Natural convection in a square enclosure heated periodically from part of the bottom wall. Numer. Heat Transf. Part A 1995, 27, 319-333. [CrossRef]

14. Lage, J.L.; Bejan, A. The Ra-Pr domain of laminar natural convection in an enclosure heated from the side. Numer. Heat Transf. Part A 1991, 19, 21-41. [CrossRef]

15. Kwak, H.S.; Kuwahara, K.; Hyun, J.M. Prediction of the resonance frequency of natural convection in an enclosure with time-periodic heating imposed on the sidewall. Int. J. Heat Mass Transf. 1998, 41, 3157-3160. [CrossRef]

16. Sarris, I.E.; Lekakis, I.; Vlachos, N.S. Natural convection in a 2D enclosure with sinusoidal upper wall temperature. Numer. Heat Transf. Part A 2002, 42, 513-530. [CrossRef]

17. Sheremet, M.A.; Pop, I. Natural convection in a square porous cavity with sinusoidal temperature distributions on both side walls filled with a nanofluid: Buongiorno's mathematical model. Transp. Porous Media 2014, 105, 411-429. [CrossRef]

18. Sheremet, M.A.; Pop, I. Natural convection in a wavy porous cavity with sinusoidal temperature distributions on both side walls filled with a nanofluid: Buongiorno's mathematical model. J. Heat Transf. 2015, 137, 072601. [CrossRef]

19. Buongiorno, J. Convective transport in nanofluids. ASME J. Heat Transf. 2006, 128, 240-250. [CrossRef]

20. Bejan, A. Second law analysis in heat transfer. Energy Int. J. 1980, 5, 721-732. [CrossRef]

21. Bejan, A. Entropy Generation through Heat and Fluid Flow; John Wiley \& Sons: Hoboken, NJ, USA, 1982.

22. Bejan, A. Entropy Generation Minimization: The Method of Thermodynamic Optimization of Finite-Size Systems and Finite-Time Processes; CRC Press: New York, NY, USA, 1995.

23. Rashidi, M.M.; Abelman, S.; Mehr, N.F. Entropy generation in steady MHD flow due to a rotating porous disk in a nanofluid. Int. J. Heat Mass Transf. 2013, 62, 515-525. [CrossRef]

24. Komurgoz, G.; Arikoglu, A.; Ozkol, I. Analysis of the magnetic effect on entropy generation in an inclined channel partially filled with porous medium. Numer. Heat Transf. Part A 2012, 61, 786-799. [CrossRef]

25. Butt, A.S.; Ali, A. Entropy effects in hydromagnetic free convection flow past a vertical plate embedded in a porous medium in the presence of thermal radiation. Eur. Phys. J. Plus 2013, 128, 51-65. [CrossRef]

26. Mahmud, S.; Fraser, R.A. Magnetohydrodynamic free convection and entropy generation in a square porous cavity. Int. J. Heat Mass Transf. 2004, 47, 3245-3256. [CrossRef]

27. Sheremet, M.A.; Oztop, H.F.; Pop, I.; Abu-Hamdeh, N. Analysis of entropy generation in natural convection of nanofluid inside a square cavity having hot solid block: Tiwari and Das' model. Entropy 2016, 18, 9. [CrossRef]

28. Sheremet, M.; Pop, I.; Öztop, H.F.; Abu-Hamdeh, N. Natural convection of nanofluid inside a wavy cavity with a non-uniform heating: Entropy generation analysis. Int. J. Numer. Methods Heat Fluid Flow 2017, 27, 958-980. [CrossRef] 
29. Bondareva, N.S.; Sheremet, M.A.; Oztop, H.F.; Abu-Hamdeh, N. Entropy generation due to natural convection of a nanofluid in a partially open triangular cavity. Adv. Powder Technol. 2017, 28, $244-255$. [CrossRef]

30. Tiwari, R.K.; Das, M.K. Heat transfer augmentation in a two-sided lid-driven differentially heated square cavity utilizing nanofluids. Int. J. Heat Mass Transf. 2007, 50, 2002-2018. [CrossRef]

31. Oztop, H.F.; Al-Salem, K. A review on entropy generation in natural and mixed convection heat transfer for energy systems. Renew. Sustain. Energy Rev. 2012, 16, 911-920. [CrossRef]

32. Nayak, R.K.; Bhattacharyya, S.; Pop, I. Numerical study on mixed convection and entropy generation of $\mathrm{Cu}-$ water nanofluid in a differentially heated skewed enclosure. Int. J. Heat Mass Transf. 2015, 85, 620-634. [CrossRef]

33. Selimefendigil, F.; Öztop, H.F. Natural convection and entropy generation of nanofluid filled cavity having different shaped obstacles under the influence of magnetic field and internal heat generation. J. Taiwan Inst. Chem. Eng. 2015, 56, 42-56. [CrossRef]

34. Kefayati, G.H.R.; Sidik, N.A.C. Simulation of natural convection and entropy generation of non-Newtonian nanofluid in an inclined cavity using Buongiorno's mathematical model (Part II, entropy generation). Powder Technol. 2017, 305, 679-703. [CrossRef]

35. Mahian, O.; Kianifar, A.; Kleinstreuer, C.; Al-Nimr, M.A.; Pop, I.; Sahin, A.Z.; Wongwises, S. A review on entropy generation in nanofluid flow. Int. J. Heat Mass Transf. 2013, 65, 514-532. [CrossRef]

36. Manca, O.; Jaluria, Y.; Poulikakos, D. Heat transfer in nanofluids. Adv. Mech. Eng. 2010, 2010, 380826. [CrossRef]

37. Choi, S.U.S. Enhancing Thermal Conductivity of Fluids with Nanoparticles. In Proceedings of the 1995 ASME International Mechanical Engineering Congress and Exposition, FED 231/MD 66, San Francisco, CA, USA, 12-17 November 1995; pp. 99-105.

38. Das, S.K.; Choi, S.U.S.; Yu, W.; Pradeep, Y. Nanofluids: Science and Technology; Wiley: Hoboken, NJ, USA, 2008.

39. Nield, D.A.; Bejan, A. Convection in Porous Media, 4th ed.; Springer: New York, NY, USA, 2013.

40. Buongiorno, J.; Venerus, D.C.; Prabhat, N.; McKrell, T.; Townsend, J.; Christianson, R.; Tolmachev, Y.V.; Keblinski, P.; Hu, L.; Alvarado, J.L.; et al. A benchmark study on the thermal conductivity of nanofluids. J. Appl. Phys. 2009, 106, 1-14. [CrossRef]

41. Mahian, O.; Kianifar, A.; Kalogirou, S.A.; Pop, I.; Wongwises, S. A review of the applications of nanofluids in solar energy. Int. J. Heat Mass Transf. 2013, 57, 582-594. [CrossRef]

42. Sivasankaran, S.; Pan, K.L. Natural Convection of Nanofluids in a Cavity with Nonuniform Temperature Distributions on Side Walls. Numer. Heat Transf. Part A 2013, 65, 247-268. [CrossRef]

43. Alsabery, A.I.; Chamkha, A.J.; Saleh, H.; Hashim, I. Transient natural convective heat transfer in a trapezoidal cavity filled with non-Newtonian nanofluid with sinusoidal boundary conditions on both sidewalls. Powder Technol. 2017, 308, 214-234. [CrossRef]

44. Alsabery, A.I.; Chamkha, A.J.; Saleh, H.; Hashim, I. Heatline visualization of conjugate natural convection in a square cavity filled with nanofluid with sinusoidal temperature variations on both horizontal walls. Int. J. Heat Mass Transf. 2016, 100, 835-850. [CrossRef]

45. Oztop, H.F.; Abu-Nada, E.; Varol, Y.; Al-Salem, K. Computational analysis of non-isothermal temperature distribution on natural convection in nanofluid filled enclosures. Superlattices Microstruct. 2011, 49, 453-467. [CrossRef]

46. Deng, Q.H.; Chang, J.J. Natural convection in a rectangular enclosure with sinusoidal temperature distributions on both side walls. Numer. Heat Transf. Part A 2008, 54, 507-524. [CrossRef]

47. Sivasankaran, S.; Bhuvaneswari, M. Natural convection in a porous cavity with sinusoidal heating on both sidewalls. Numer. Heat Transf. Part A 2013, 63, 14-30. [CrossRef]

48. Magherbi, M.; Abbassi, H.; Hidouri, N.; Ben Brahim, A. Second law analysis in convective heat and mass transfer. Entropy 2006, 8, 1-17. [CrossRef]

(C) 2017 by the authors. Licensee MDPI, Basel, Switzerland. This article is an open access article distributed under the terms and conditions of the Creative Commons Attribution (CC BY) license (http:/ / creativecommons.org/licenses/by/4.0/). 